\title{
TERMINOLOGY: TECHNICAL
}

base word

bisemantic compound

bound clause

Bugge-Sieversche Regel

Craigie's law

elision

empty rhymes

enclisis

enjambment

extraposition

formwords

hard sentence boundaries nominative substantive member of a kenning that is modified by a genitival qualifier

"Kompositum mit doppelter begrifflicher Kraft" (Andreas Heusler); compound that can be paraphrased in the sequence $\mathrm{Q}+\mathrm{BW}$ or as a verbal phrase "gebundener Satz" (Hans Kuhn); sentence introduced by an introductory element (conjunction, adverb)

rule positing vowel shortening in hiatus

rule stating that no long nomen is permitted in positions 3 or 4 in even dróttkvaett lines if the first two positions are occupied by two long nominal syllables; in odd lines, no nomen is permitted in those positions if alliteration falls in positions 1 and 5 and positions 1-2 are occupied by two long nomina

poetic license according to which an extra proclitic syllable can occur in an $X$-position

internal rhymes in which the vowels rhyme and the postvocalic environment is not identical

post-position of words and particles

straddling of the metrical caesura by elements belonging to the same syntactic unit

constituent or parts of a constituent occurring outside the frame of the sentence, that is, they are embedded in a previous clause

"Formwörter" (Andreas Heusler), "Satzteilpartikeln" (Hans Kuhn); prepositions, proclitic particles, and the definite article $e n n$

“harte Satzgrenzen" (Hans Kuhn); sentence boundaries not followed by an introductory element 
heavy dips

hiatus

inverted kenningar

law of the caesura

law of sentence introduction

law of sentence particles

monosemantic compound

neutralization
nomina
one-line clause

proclisis

resolution

rule of syntactic coherence

sectional clause

sentence-concluding pattern sentence-continuing pattern

sentence-introductory pattern

sentence particles "schwere Senkungen" (Hans Kuhn); long nominal syllables occurring in $X$-positions

concurrence of vowel sounds in two successive syllables nominal circumlocutions consisting of a sequence of three consecutive elements, in which the first modifies the third or the third modifies the first

"Zäsurgesetz" (Hans Kuhn); law according to which all dróttkvaett lines are divided by a syntactic caesura, which in odd lines falls between the alliterating staves, in even lines between the syllables with internal rhyme

"Satzspitzengesetz"; "Kuhn's second law" to the effect that sentence particles must stand in anacrusis

"Satzpartikelgesetz"; "Kuhn's first law" to the effect that sentence particles (i.e., all unstressed or weakly stressed words that are not syntactically bound but function as syntactically independent constituents) stand in the first dip of the sentence, proclitically to either the first or the second stressed word

"Kompositum mit einfacher begrifflicher Kraft" (Andreas

Heusler); compound that cannot be paraphrased in the sequence $\mathrm{Q}+\mathrm{BW}$

two short nomina occupying a short position $(x x=x)$

nouns, adjectives, infinitives, participles I-II

parenthetic clause that occupies one dróttkvatt line (lines 2-4)

words or particles in pre-position two short syllables occupying a long position $(\breve{x} \times=\bar{x})$

(Hans Kuhn); rule according to which the nonalliterating lift falling between two alliterating lifts in odd lines belongs syntactically to the first lift

parenthetic clause in lines 2-4 that occupies part of a dróttkvaett line

type of syntactic filler that concludes a sentence

type of syntactic filler whose elements continue a sentence introduced in an earlier line

type of syntactic filler whose initial position introduces a new clause

"Satzpartikeln" (Hans Kuhn); all unstressed or weakly stressed words that are not syntactically bound (formwords) but function as syntactically independent constituents 
soft sentence boundaries unterepische Füllungen

vertical placement

×-position sentence boundaries followed by an introductory element (Andreas Heusler); alliterative half-lines with fewer than four syllables

"Tiefstellung" (Konstantin Reichardt); disrupted parts of syntactic units occurring below each other in the halfstanza.

metrical position occupied by a formword or an inflectional ending 